\title{
AFLATOXINAS EM PRODUTOS À BASE DE MILHO COMERCIALIZADOS NO BRASIL E RISCOS PARA A SAÚDE HUMANA ${ }^{1}$
}

\author{
Kassia Ayumi Segawa do AMARAL ${ }^{2}$, Gabriel Bassaga NASCIMENTO², Beatriz Leiko SEKIYAMA², \\ Vanderly JANEIRO ${ }^{3}$, Miguel MACHINSKI $\mathrm{JR}^{2, *}$
}

\begin{abstract}
RESUMO
As aflatoxinas são metabólitos secundários tóxicos, produzidos por fungos do gênero Aspergillus. As técnicas de ensaio imunoenzimático (ELISA) e cromatografia em camada delgada (CCD) foram utilizadas na determinação de aflatoxina total, em produtos alimentícios à base de milho comercializados em Maringá e Marialva, Paraná, Brasil, entre abril de 2003 e março de 2004. Foram analisadas 123 amostras, das quais sete apresentaram-se positivas na CCD e 16 no ELISA. O valor médio de aflatoxina total encontrado nas amostras utilizando-se a CCD foi $0,62 \mu \mathrm{g} / \mathrm{kg}$, enquanto que pela técnica ELISA foi encontrado o valor de $0,78 \mu \mathrm{g} / \mathrm{kg}$. Os resultados apresentaram diferenças significativas entre ELISA e CCD $(T=12, p=0,0469)$. Os dados demonstraram baixa ocorrência de aflatoxinas nos produtos à base de milho analisados. Entretanto, a Ingestão Diária Provável Média (IDP $\left.{ }_{M}\right)$ de $A_{F B} B_{1}$ foi acima da Ingestão Diária Tolerável (IDT), indicando um risco de hepatocarcinogenicidade na população brasileira da Região Sul do Brasil, devido ao consumo de produtos à base de milho. O método ELISA mostrou-se simples, rápido e com menor uso de solventes orgânicos, porém apresentou resultados presuntivos positivos e negativos, tornando necessária a confirmação da identidade das micotoxinas pesquisadas por CCD.
\end{abstract}

Palavras-chave: micotoxinas, aflatoxinas, ELISA, cromatografia em camada delgada, avaliação de risco.

\section{SUMMARY}

AFLATOXINS IN CORN-BASED FOOD PRODUCTS TRADED IN BRAZIL AND RISKS TO HUMAN HEALTH. Aflatoxins are secondary toxic mold metabolites produced by Aspergillus. The techniques of immunoassay (ELISA) and thin layer chromatography (TLC) were used for the determination of total aflatoxins in foodstuffs produced with maize and commercialized in Brazil, between April 2003 and March 2004. One hundred and twenty-three samples of foodstuffs produced with maize were analized. Seven of which were positive in TLC and 16 in ELISA. The average of total aflatoxin found in samples using TLC was $0.62 \mu \mathrm{g} / \mathrm{kg}\left(\mu \mathrm{g} . \mathrm{kg}^{-1}\right)$, while using ELISA was $0.78 \mu \mathrm{g} / \mathrm{kg}\left(\mu \mathrm{g} . \mathrm{kg}^{-1}\right)$. The results presented significant differences between ELISA and TLC (T=12, $\left.\mathrm{p}=0.0469\right)$. The data demonstrate low occurence of aflatoxins in the maize products analysed. Despite this, Average Probable Daily Intake (APDI) of AFB was above Tolerable Daily Intake (TDI), indicating a risk of liver carcinogenicity for Brazilian population due to the consumption of maize products. The ELISA method revealed to be simple, fast, and uses less organic solvent, however, it presented positive and negative presumptive results, what makes necessary the confirmation of the mycotoxins identity by TLC.

Keywords: mycotoxins, aflatoxins, ELISA, thin-layer chromatography, risk assessment.

\section{1 - INTRODUÇÃO}

A presença de micotoxinas em alimentos é um sério problema para saúde pública e para a qualidade dos alimentos. Por muitos anos, os fungos foram conhecidos pela sua capacidade de produzir metabólitos tóxicos, porém os seus efeitos foram largamente ignorados, tornando as micotoxicoses negligenciadas. Esta situação foi alterada drasticamente após 1960, com a doença X dos perus, quando a atenção mundial se concentrou sobre as micotoxinas. A rapidez na identificação e caracterização das aflatoxinas e a demonstração da aflatoxina $\mathrm{B}_{1}$ como um carcinógeno extremamente potente ao ser humano e animal, impulsionaram esta mudança [20].

\footnotetext{
${ }^{1}$ Recebido para publicação em 21/3/2005. Aceito para publicação em 28/4/2006 (001487)

${ }^{2}$ Universidade Estadual de Maringá, Departamento de Análises Clínicas, Laboratório de Toxicologia

Avenida Colombo, 5.790. CEP 87.020-900 - Maringá (PR)

${ }^{3}$ Universidade Estadual de Maringá, Departamento de Estatística
}

As aflatoxinas são um grupo de micotoxinas de intensa importância em alimentos e rações. Os principais fungos toxigênicos produtores de aflatoxinas são: Aspergillus flavus, A. parasiticus e A. nomius [34, 47]. A. flavus produz apenas aflatoxinas do grupo B, enquanto A. parasiticus e A. nomius produzem aflatoxinas dos grupos B e G [10]. As quatro aflatoxinas naturalmente encontradas são: $\mathrm{B}_{1}\left(\mathrm{AFB}_{1}\right), \mathrm{B}_{2}\left(\mathrm{AFB}_{2}\right), \mathrm{G}_{1}\left(\mathrm{AFG}_{1}\right)$ e $\mathrm{G}_{2}\left(\mathrm{AFG}_{2}\right)$ [48]. A importância das micotoxinas se deve aos danos provocados à saúde humana e animal, e também aos prejuízos econômicos na agricultura [28, 33].

O maior problema decorre da ação crônica das aflatoxinas no homem, pois além da alteração do crescimento em jovens e crianças, ocasionam distúrbios neurológicos, imunológicos e o aparecimento de câncer hepático [11, $15,25,43$ ]. O risco da população se deve aos seus efeitos carcinogênicos, mutagênicos, teratogênicos e hepatotóxicos $[43,50]$. Dados epidemiológicos demonstram uma associação das aflatoxinas com a síndrome de Reye e o Kwashiorkor 
[36]. A aflatoxina $B_{1}$ é considerada um potente carcinógeno pertencente ao grupo 1 segundo classificação da International Agency for Research on Cancer - IARC [39].

Os principais substratos para a produção dessas toxinas são os cereais, cujas perdas, segundo estimativa da Food and Agriculture Organization of the United Nations - FAO [13], situam-se ao redor de $25 \%$ dos grãos produzidos. Existem muitos tipos de micotoxinas, sendo que seis são consideradas importantes do ponto de vista de saúde pública: aflatoxina $\left(\mathrm{AFB}_{1}, \mathrm{AFB}_{2}, \mathrm{AFG}_{1}\right.$ e $\mathrm{AFG}_{2}$ ), ocratoxina $A$, patulina, fumonisina, deoxinivalenol e zearalenona [13].

A pequena quantidade de dados existentes no Brasil, sobre a ocorrência de micotoxinas em alimentos, é decorrente do alto custo dos equipamentos analíticos, da escassez de mão-de-obra especializada na área de análise, bem como das dificuldades no plano de amostragem [44].

Atualmente, as aflatoxinas têm sido detectadas por técnicas físico-químicas e biológicas [12]. Dentre as técnicas físico-químicas estão a cromatografia em camada delgada, a cromatografia líquida de alta eficiência e a cromatografia gasosa; e as técnicas biológicas incluem os imunoensaios, como as colunas de imunoafinidade e ELISA [3, 5, 9, 22, 40].

Este trabalho teve como objetivos: pesquisar a ocorrência de aflatoxinas em produtos alimentícios à base de milho, comercializadas em Maringá e Marialva, avaliar o risco à saúde pública pela exposição a estas micotoxinas e comparar duas técnicas de quantificação de aflatoxinas: a cromatografia em camada delgada (CCD) e o ensaio imunoenzimático (ELISA), em produtos alimentícios à base de milho.

\section{2 - MATERIAL E MÉTODOS}

\section{1 - Amostras}

Entre abril de 2003 e março de 2004, foram coletadas 123 amostras de produtos alimentícios à base de milho, comercializados nas cidades de Maringá e Marialva, Estado do Paraná, Brasil. As amostras foram divididas em oito grupos, de acordo com o tipo e aspecto físico (Quadro 1). O peso mínimo da amostra foi de $500 \mathrm{~g}$. As amostras foram moídas, homogeneizadas e estocadas a $-20^{\circ} \mathrm{C}$ até a análise.

\section{2 - Padrões analíticos}

Os padrões de micotoxinas foram adquiridos pela Sigma Chemical Co. (EUA), e o preparo de suas soluções estoque e de uso foi realizado segundo descrição no Manual de Métodos Oficiais de Análises da AOAC [4]. A partir das soluções estoque individuais para cada toxina e após a determinação das concentrações por espectrofotometria no ultravioleta, foi preparada a solução de trabalho com uma mistura das toxinas: $5 \mu \mathrm{g} / \mathrm{mL}$ para $A_{F B}$ e $A_{1 F}, 1,5 \mu \mathrm{g} / \mathrm{mL}$ para $\mathrm{AFB}_{2}$ e $\mathrm{AFG}_{2}$, em benzeno:acetonitrila (98:2).
QUADRO 1 - Grupos de alimentos à base de milho, segundo o tipo e aspecto físico, adquiridos no comércio de Maringá e Marialva, entre abril de 2003 e março de 2004

\begin{tabular}{|c|c|c|}
\hline Grupo & Tipo de alimento & $\begin{array}{l}\text { Quantidade } \\
\text { (n) }\end{array}$ \\
\hline Grupo 1 & $\begin{array}{l}\text { Fubá, fubá de canjica, fubá mimoso e curau de } \\
\text { milho }\end{array}$ & 28 \\
\hline Grupo 2 & $\begin{array}{l}\text { Farinha de milho, flocos de milho pré-cozido, } \\
\text { farinha em flocos de milho, flocos de milho, } \\
\text { polenta pré-cozida e farinha de milho - tipo biju }\end{array}$ & 22 \\
\hline Grupo 3 & $\begin{array}{l}\text { Quirera de milho, canjiquinha, canjiquinha } \\
\text { amarela, canjiquinha de milho, fubá italiano } \\
\text { - semolina e canjiquinha }\end{array}$ & 17 \\
\hline Grupo 4 & Pipoca & 19 \\
\hline Grupo 5 & $\begin{array}{l}\text { Canjica branca, canjica de milho e canjica } \\
\text { amarela }\end{array}$ & 12 \\
\hline Grupo 6 & Polenta pronta & 03 \\
\hline Grupo 7 & Corn flakes, sucrilhos e pipoca açucarada & 11 \\
\hline Grupo 8 & Salgadinho de milho & 11 \\
\hline
\end{tabular}

\section{3 - Métodos}

\subsection{1 - Cromatografia em Camada Delgada (CCD)}

A determinação de aflatoxinas foi realizada segundo o método descrito por SOARES \& RODRIGUEZ-AMAYA [45]. Cinqüenta gramas da amostra foram homogeneizadas em blender (Waring Co., EUA) com $270 \mathrm{~mL}$ de metanol e $30 \mathrm{~mL}$ de cloreto de potássio 4\%, durante 5 min. A mistura foi filtrada em papel filtro comum. Cento e cinqüenta $\mathrm{mL}$ do filtrado foram transferidos para um béquer onde foram adicionados $150 \mathrm{~mL}$ de sulfato de amônio $30 \%$ e $50 \mathrm{~mL}$ de celite, durante $5 \mathrm{~min}$. A mistura foi filtrada em papel filtro comum. Cento e cinqüenta $\mathrm{mL}$ do filtrado foram transferidos para um funil de separação e adicionados de $150 \mathrm{~mL}$ de água. Essa mistura foi particionada duas vezes com $10 \mathrm{~mL}$ de clorofórmio. Cinco $\mathrm{mL}$ da primeira e da segunda partição de clorofórmio foram combinados e evaporados à secura em banho de água a $80^{\circ} \mathrm{C}$. O resíduo obtido foi dissolvido em $200 \mu \mathrm{L}$ de benzeno:acetonitrila (98:2).

Para triagem, foram aplicados $5 \mu \mathrm{L}$ do extrato na cromatoplaca (Alugram ${ }^{\circledR}$ Sil G -sílicagel 60G, Macherey-Nagel, Germany) a $2 \mathrm{~cm}$ da base. Os padrões foram aplicados separadamente. A placa foi colocada em uma cuba não saturada contendo tolueno:acetato de etila:clorofórmio:ácido fórmico (70:50:50:20, v/v/v/v) até atingir $10 \mathrm{~cm}$, segundo GIMENO [17]. As aflatoxinas foram visualizadas por incidência da luz UV longa. Para quantificação, foram aplicados volumes conhecidos de amostra e padrões nas cromatoplacas. Para a quantificação das aflatoxinas, as placas foram desenvolvidas no sistema-solvente descrito acima. Os cálculos foram realizados de acordo com o Manual de Métodos Oficiais de Análises da AOAC [4].

A identidade das toxinas foi confirmada por reações de derivação e avaliação com os padrões por cromatografia em camada delgada. As aflatoxinas foram derivadas com ácido trifluoroacético segundo PRZYLBYLSKI [42]. 


\subsection{2 - Ensaio imunoenzimático}

Para a técnica imunoenzimática foi utilizado o Kit AgraQuant $^{\mathrm{TM}}$ Total Aflatoxin Assay 4/40 fornecido pela Romer Laboratories ${ }^{\circledR}$ (Singapore), o qual determina a quantidade de aflatoxina total. A extração das aflatoxinas foi feita pela adição de $100 \mathrm{~mL}$ de metanol $70 \%$ a $20 \mathrm{~g}$ da amostra. Uma quantidade de $100 \mu \mathrm{L}$ do extrato foi adicionada a $200 \mu \mathrm{L}$ do conjugado nas cavidades de uma placa de diluição. Os padrões foram diluídos da mesma maneira. Após cuidadosa homogeneização, $100 \mu \mathrm{L}$ do conteúdo de cada cavidade de diluição foram transferidos para a cavidade revestida de anticorpos. Após 15 min de incubação à temperatura ambiente, as cavidades foram lavadas com água deionizada e foram adicionados $100 \mu \mathrm{L}$ do substrato em cada cavidade. Após 5 min de incubação à temperatura ambiente, foram adicionadas $100 \mu \mathrm{L}$ da solução bloqueadora em cada cavidade. A determinação quantitativa foi feita em uma leitora de placas Stat Fax 303 Plus (Awareness technology, Inc. - EUA) com filtro de $450 \mathrm{~nm}$.

\section{4 - Controle da qualidade analítica}

Todas as amostras foram analisadas em duplicata. As duplicatas foram analisadas em dias diferentes. Cada conjunto de nove amostras foi acompanhado com uma amostra enriquecida artificialmente, isto é, para as amostras extraídas no mesmo dia uma quantidade de micotoxinas foi adicionada em uma amostra conhecida no dia anterior a extração. Estas amostras foram usadas para avaliar a recuperação e para a quantificação, assim todos os resultados foram corrigidos pela recuperação encontrada. Os seguintes critérios de qualidade analítica foram definidos: a recuperação deveria estar entre 65 a 135\% e o coeficiente de variação entre a duplicata inferior a $30 \%$.

\section{5 - Determinação da Ingestão Diária Provável Média (IDP ${ }_{M}$ )}

Segundo HERRMAN \& YOUNES [24], a $\operatorname{IDP}_{\mathrm{M}}$ é calculada utilizando a concentração média de $\mathrm{AFB}_{1}$ encontrada nas amostras analisadas multiplicado pela quantidade ingerida diariamente do alimento, dividida pelo peso corpóreo de uma pessoa adulta, ou seja, $70 \mathrm{~kg}$.

\section{6 - Análise estatística}

A comparação das duas técnicas empregadas foi realizada pelo teste não-paramétrico dos postos com sinais de Wilcoxon [14].

\section{3 - RESULTADOS E DISCUSSÃo}

A recuperação média do método foi de 109,5 \% para as aflatoxinas, conforme demonstra a Tabela 1. Os limites de detecção foram: $3,2 \mu \mathrm{g} / \mathrm{kg}, 1,4 \mu \mathrm{g} / \mathrm{kg}, 3,2 \mu \mathrm{g} / \mathrm{kg}$ e $0,5 \mu \mathrm{g} / \mathrm{kg}$, respectivamente para a $\mathrm{AFB}_{1}, \mathrm{AFB}_{2}, \mathrm{AFG}_{1}$ e $\mathrm{AFG}_{2}$. Os resultados foram semelhantes aos encontrados por vários autores. Os limites de detecção obtidos por MILANEZ et al. [32] para o método CCD foram $2,5 \mu \mathrm{g} / \mathrm{kg}$ para $\mathrm{AFB}_{1}$ e $\mathrm{AFG}_{1}$ e $1,0 \mu \mathrm{g} / \mathrm{kg}$ para $\mathrm{AFB}_{2}$ e $\mathrm{AFG}_{2}$. FURLONG et al. [15] verificaram que o limite de detecção para $\mathrm{AFB}_{1}$, varia conforme a matriz da amostra: arroz branco $2,5 \mu \mathrm{g} / \mathrm{kg}$, farinha de trigo 1,9 $\mu \mathrm{g} / \mathrm{kg}$ e fubá $4,0 \mu \mathrm{g} / \mathrm{kg}$. VARGAS et al. [49], utilizando CCD com detecção por densitometria de fluorescência, obtiveram os seguintes limites de detecção e recuperação para amostras adicionadas com $\mathrm{AFB}_{1}, \mathrm{AFB}_{2}, \mathrm{AFG}_{1}$ e $\mathrm{AFG}_{2}: 0,20 \mu \mathrm{g} / \mathrm{kg}$ e $94 \%, 0,10 \mu \mathrm{g} / \mathrm{kg}$ e $85 \%, 0,19 \mu \mathrm{g} / \mathrm{kg}$ e $94 \%$ e $0,10 \mu \mathrm{g} / \mathrm{kg}$ e $97 \%$, respectivamente.

TABELA 1 - Recuperação de amostras de produtos de milho enriquecida com aflatoxinas $\mathrm{B}_{1}, \mathrm{~B}_{2}, \mathrm{G}_{1}$ e $\mathrm{G}_{2}$

\begin{tabular}{|c|c|c|c|c|c|c|c|c|}
\hline \multirow[t]{2}{*}{ Grupo } & \multicolumn{2}{|c|}{$\mathrm{AFB}_{1}$} & \multicolumn{2}{|c|}{$\mathrm{AFB}_{2}$} & \multicolumn{2}{|c|}{$\mathrm{AFG}_{1}$} & \multicolumn{2}{|c|}{$\mathrm{AFG}_{2}$} \\
\hline & 1 & 2 & 1 & 2 & 1 & 2 & 1 & 2 \\
\hline \multirow[t]{3}{*}{1} & 24,0 & 32,0 & 7,2 & 9,6 & 24,0 & 32,0 & 7,2 & 9,6 \\
\hline & 16,0 & 16,0 & 4,8 & 4,8 & 16,0 & 16,0 & 4,8 & 4,8 \\
\hline & 20,0 & 21,3 & 6,0 & 6,4 & 20,0 & 21,3 & 6,0 & 6,4 \\
\hline \multirow[t]{2}{*}{2} & 16,0 & 10,7 & 4,8 & 3,2 & 16,0 & 10,7 & 4,8 & 3,2 \\
\hline & 16,0 & 16,0 & 4,8 & 4,8 & 16,0 & 16,0 & 4,8 & 4,8 \\
\hline \multirow[t]{2}{*}{3} & 24,0 & 32,0 & 7,2 & 9,6 & 24,0 & 32,0 & 7,2 & 9,6 \\
\hline & 16,0 & 21,3 & 4,8 & 6,4 & 16,0 & 21,3 & 4,8 & 6,4 \\
\hline \multirow[t]{2}{*}{4} & 24,0 & 32,0 & 7,2 & 9,6 & 24,0 & 32,0 & 7,2 & 9,6 \\
\hline & 20,0 & 16,0 & 6,0 & 4.8 & 20,0 & 16,0 & 6,0 & 4,8 \\
\hline \multirow[t]{2}{*}{5} & 16,0 & 16,0 & 4,8 & 4,8 & 16,0 & 16,0 & 4,8 & 4,8 \\
\hline & 24,0 & 32,0 & 7,2 & 9,6 & 24,0 & 32,0 & 7,2 & 9,6 \\
\hline 7 & 32,0 & 32,0 & 9,6 & 9,6 & 32,0 & 32,0 & 9,6 & 9,6 \\
\hline \multirow[t]{2}{*}{8} & 20,0 & 21,3 & 6,0 & 6,4 & 20,0 & 21,3 & 6,0 & 6,4 \\
\hline & 20,0 & 21,3 & 6,0 & 6,4 & 20,0 & 21,3 & 6,0 & 6,4 \\
\hline $\begin{array}{l}\text { RECUPERAÇÃO } \\
\text { MÉDIA }\end{array}$ & (\%) & 109,5 & & 109,5 & & 109,5 & & 109,5 \\
\hline
\end{tabular}

1 - Quantidade de micotoxinas adicionada em $\mu \mathrm{g} / \mathrm{kg} ; 2$ - Quantidade de micotoxinas encontrada em $\mu \mathrm{g} / \mathrm{kg}$

Do total de 123 amostras de alimentos à base de milho, sete mostraram-se positivas para aflatoxinas pelo método de CCD, e 16 pelo método imunoenzimático (Figura 1). O grupo 1 dos alimentos analisados apresentou maior número de amostras positivas conforme descrito na Figura 1 e nas Tabelas 2 e 3.

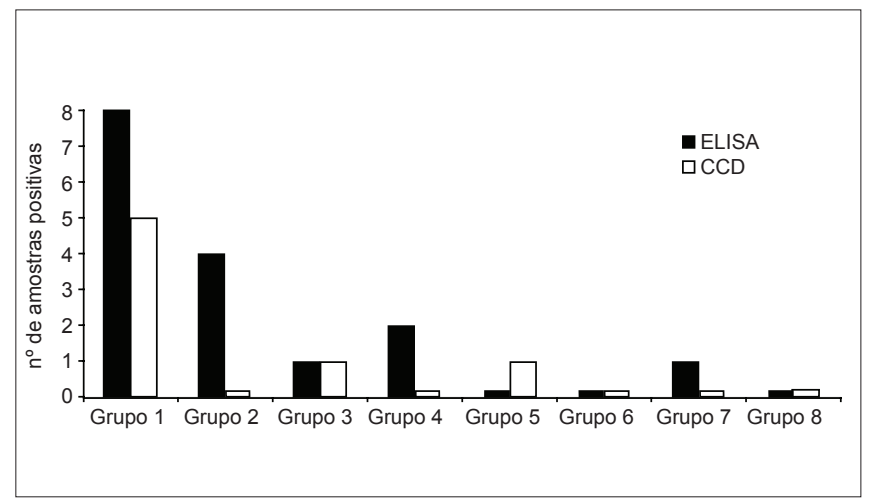

FIGURA 1 - Número de amostras positivas encontradas em produtos alimentícios à base de milho em análises realizadas por CCD e ELISA. Os produtos foram adquiridos no comércio de Maringá e Marialva, entre abril de 2003 e março de 2004, e distribuídos em grupos 
TABELA 2 - Teores de aflatoxinas encontrados por CCD em produtos alimentícios à base de milho, distribuídos em grupos e adquiridos no comércio de Maringá e Marialva, entre abril de 2003 e março de 2004

\begin{tabular}{lcccc}
\hline Grupo & $\mathbf{N}^{\circ}$ de amostras & $\begin{array}{c}\mathbf{N}^{\circ} \text { de amostras } \\
\text { positivas }\end{array}$ & $\begin{array}{c}\text { Aflatoxinas } \\
(\mu \mathbf{g} / \mathbf{k g})\end{array}$ & $\begin{array}{c}\text { Média } \\
(\mu \mathbf{g} / \mathbf{k g})\end{array}$ \\
\hline Grupo 1 & 28 & 5 & $3,3-17,2$ & 7,86 \\
Grupo 2 & 22 & - & - & - \\
Grupo 3 & 17 & 1 & 23,9 & 23,9 \\
Grupo 4 & 19 & - & - & - \\
Grupo 5 & 12 & 1 & 13,3 & 13,3 \\
Grupo 6 & 3 & - & - & - \\
Grupo 7 & 11 & - & - & - \\
Grupo 8 & 11 & - & - & - \\
\hline
\end{tabular}

TABELA 3 - Teores de aflatoxinas encontrados por ELISA em produtos alimentícios à base de milho, distribuídos em grupos e adquiridos no comércio de Maringá e Marialva, entre abril de 2003 e março de 2004

\begin{tabular}{lcccc}
\hline Grupos & $\begin{array}{c}\mathbf{N}^{\circ} \text { de } \\
\mathbf{a m o s t r a s}\end{array}$ & $\begin{array}{c}\mathbf{N}^{\circ} \text { de amostras } \\
\text { positivas }\end{array}$ & $\begin{array}{c}\text { Aflatoxinas } \\
(\boldsymbol{\mu} \mathbf{g} / \mathbf{k g})\end{array}$ & $\begin{array}{c}\text { Média } \\
(\boldsymbol{\mu g} / \mathbf{k g})\end{array}$ \\
\hline Grupo 1 & 28 & 8 & $4,1-9,8$ & 5,55 \\
Grupo 2 & 22 & 4 & $4,5-6,2$ & 5,12 \\
Grupo 3 & 17 & 1 & 13,7 & 13,7 \\
Grupo 4 & 19 & 2 & $4,3-4,8$ & 4,55 \\
Grupo 5 & 12 & - & - & - \\
Grupo 6 & 3 & - & - & - \\
Grupo 7 & 11 & 1 & 4,8 & 4,8 \\
Grupo 8 & 11 & - & - & - \\
\hline
\end{tabular}

Os resultados encontrados para aflatoxinas foram semelhantes aos encontrados por vários autores. FURLONG et al. [15] relataram que 7,7\% das 39 amostras analisadas apresentaram contaminação por aflatoxinas. PICH et al. [41] encontraram níveis de 3 a $25 \mu \mathrm{g} / \mathrm{kg}$ em 29 amostras de farinha de milho analisadas. SOARES \& RODRIGUEZAMAYA [45] verificaram que cinco amostras das 130 analisadas continham de 20 a $47 \mu \mathrm{g} / \mathrm{kg}$ de $\mathrm{AFB}_{1}$ em diversos produtos derivados do milho.

Os produtos derivados de milho apresentaram baixa contaminação por aflatoxinas, apenas 5,7\% das amostras foram positivas por CCD. Estes resultados foram parcialmente semelhantes às pesquisas realizadas no exterior, como as relatadas por SOLOVEY et al. [46], nas quais não houve detecção de aflatoxinas em 37 amostras de alimentos derivados de milho provenientes da Argentina, e as de ABDULKADAR et al. [1], que observaram contaminação de 1,0 a $20 \mu \mathrm{g} / \mathrm{kg}$ em três das 54 amostras de milho e derivados provenientes do Catar.

O teor de contaminação dos produtos derivados do milho com aflatoxinas foi consideravelmente menor que o encontrado para o milho não processado. Vários estudos comprovam esta afirmação: ALI et al. [2] relataram um total de $69 \%$ de amostras da Indonésia contaminadas com níveis médios de $119 \mu \mathrm{g} / \mathrm{kg}$; BHAT et al. [6] observaram 25,8 \% de amostras contaminadas com quantidades superiores a $30 \mu \mathrm{g} / \mathrm{kg}$ na Índia; GLÓRIA et al. [19] verificaram 33\% de contaminação das amostras provenientes de cinco Estados brasileiros; VARGAS et al. [49] relataram 38,3\% de contaminação de amostras de diferentes regiões brasileiras com níveis médios de 9,4 $\mu \mathrm{g} / \mathrm{kg}$; HENNIGEN e DICK [23] relataram 30,5\% de amostras provenientes do Rio Grande do Sul, Brasil, com níveis variáveis de 10 a $906 \mu \mathrm{g} / \mathrm{kg}$; LI et al. [29] observaram, na China, 35\% de amostras contaminadas com níveis médios de $82 \mu \mathrm{g} / \mathrm{kg}$; MACHINSKI JR et al. [30] encontraram 54,5\% de amostras cultivadas em campos experimentais do Estado de São Paulo, Brasil, com níveis de 6 a $1600 \mu \mathrm{g} / \mathrm{kg}$; MEDINA-MARTINEZ E MARTINEZ [31 ] verificaram contaminação em 16,6\% das amostras analisadas provenientes da Venezuela; ONO et al. [38] relataram $11,3 \%$ de amostras contaminadas de origem brasileira com níveis médios de $190 \mu \mathrm{g} / \mathrm{kg}$; NEPOTE, PIONTELLI, SAUBOIS [35] observaram 10\% de contaminação com amostras provenientes da Argentina com concentrações acima de $20 \mu \mathrm{g} / \mathrm{kg}$; e, também na Argentina, GONZALEZ et al. [21] não observaram contaminação por aflatoxinas nas 30 amostras analisadas.

Das 123 amostras analisadas, 104 apresentaram resultados negativos pelos dois métodos. O método imunoenzimático apresentou 12 resultados falso-positivos e três resultados falso-negativos (Tabela 4). Os imunoensaios têm apresentado resultados falso-positivos [37], e podem ocorrer resultados falso-negativos [18]. Ao comparar o ELISA com a CCD, o teste dos postos com sinais de Wilcoxon foi $\mathrm{T}=12$ $\mathrm{e} \mathrm{p}=0,0469$, portanto há diferença entre os dois métodos (Tabela 4). Sendo assim, faz-se necessário a confirmação dos resultados obtidos com o teste imunoenzimático pelo método cromatográfico.

TABELA 4 - Aplicação do teste de Wilcoxon na comparação dos resultados encontrados por CCD e ELISA em produtos alimentícios a base de milho adquiridos no comércio de Maringá e Marialva, abril de 2003 a março de 2004

\begin{tabular}{lccc}
\hline & CCD negativo & CCD positivo & Total \\
\hline ELISA negativo & 104 & 3 & 107 \\
ELISA positivo & 12 & 4 & 16 \\
\hline TOTAL & $\mathbf{1 1 6}$ & $\mathbf{7}$ & $\mathbf{1 2 3}$ \\
\hline
\end{tabular}

Embora as quantidades de aflatoxinas encontradas nas amostras estejam abaixo do permitido pela legislação brasileira [7, 8], com exceção de uma amostra do grupo três (43 $\mu \mathrm{g} / \mathrm{kg}$ aflatoxinas totais), esses dados são de extrema importância, pois mesmo em pequenas quantidades, as aflatoxinas podem causar problemas de saúde em longo prazo.

As concentrações médias de aflatoxina total e $\mathrm{AFB}_{1}$, encontradas nas amostras utilizando a CCD, foram 0,62 e $0,57 \mu \mathrm{g} / \mathrm{kg}$, respectivamente. Segundo a tabela Global Environment Monitoring System - Food Contamination Monitoring and Assessment Programme [16], a ingestão diária de milho e derivados é de 42 g/pessoa na América do Sul [16]. Considerando o peso médio da população adulta como sendo 70 kg, a Ingestão Diária Provável Média $\left(\mathrm{IDP}_{\mathrm{M}}\right)$ de $\mathrm{AFB}_{1}$ foi de $0,34 \mathrm{ng} / \mathrm{Kg}$ p.c./dia. Portanto, a 
ingestão média estimada de $\mathrm{AFB}_{1}$ foi maior que a Ingestão Diária Tolerável (IDT), que é de 0,15 ng/Kg p.c./dia segundo KUIPER-GOODMAN [27].

Segundo os dados da dieta da população brasileira, do Instituto Brasileiro de Geografia e Estatística (IBGE) [26], o fubá é considerado o principal produto do milho consumido pela população de baixa renda. A média de aquisição alimentar domiciliar per capita diária de fubá de milho no Brasil é de 9 g. Esta quantidade varia de 13,7 g para famílias com renda de até 1,5 salários-mínimos a 2,5 g para aquelas com renda superior a 23 salários-mínimos vigente no Brasil.

Considerando que a concentração média de $\mathrm{AFB}_{1}$ em fubá neste estudo foi de $1,08 \mu \mathrm{g} / \mathrm{kg}$, a Ingestão Diária Provável Média $\left(\mathrm{IDP}_{\mathrm{M}}\right.$ ) é de $0,14 \mathrm{ng} / \mathrm{Kg}$ p.c./dia no Brasil, variando de 0,21 ng/kg p.c./dia para famílias de menor renda a $0,04 \mathrm{ng} / \mathrm{kg}$ p.c./dia para aquelas com a maior renda. Além disso, nota-se que a quantidade per capita adquirida diariamente deste produto também varia de acordo com a região geográfica como demonstrado na Tabela 5, ou seja, a Região Nordeste é a que adquire maior quantidade diária do produto ( 17 g) enquanto a Região Centro-Oeste é a de menor consumo (2,5 g).

Ao analisarmos as diferentes regiões do Brasil, verificamos que a IDP ${ }_{M}$ para a região nordeste seria de $0,26 \mathrm{ng} / \mathrm{Kg}$ p.c./dia acima da IDT proposta por KUIPER-GOODMAN [27]. Este dado corrobora no incremento de incidência de carcinoma hepatocelular; portanto, há um risco significativo à saúde pública brasileira decorrente da exposição crônica à $\mathrm{AFB}_{1}$ pela dieta com alimentos derivados do milho, em especial o fubá.

TABELA 5 - Avaliação de risco pela exposição à aflatoxina B1 em fubá nas diversas regiões do Brasil, considerando a aquisição diária deste alimento pela Pesquisa de Orçamentos Familiares do IBGE e o resultado médio de $1,08 \mu \mathrm{g} / \mathrm{kg}$ encontrado no comércio de Maringá e Marialva, no período de abril de 2003 a março de 2004

\begin{tabular}{lcr}
\hline Região do Brasil & $\begin{array}{c}\text { Aquisição per capita } \\
\text { diária de fubá (gramas) }\end{array}$ & $\begin{array}{r}\text { Ingestão Diária } \\
\text { Provável Média } \\
\text { (ng/kg p.c./dia) }\end{array}$ \\
\hline Nordeste & 17,0 & 0,26 \\
Sul & 7,7 & 0,12 \\
Sudeste & 6,1 & 0,09 \\
Norte & 4,7 & 0,07 \\
Centro-Oeste & 2,5 & 0,04 \\
\hline
\end{tabular}

\section{4 - CONCLUSÕES}

O consumo de produtos à base de milho oferece riscos à saúde da população brasileira devido à presença das aflatoxinas; sendo, portanto, necessário implantar um programa de monitoramento para micotoxinas neste tipo de alimento, principalmente para a população de baixa renda e da Região Nordeste, que apresentam um maior risco de câncer hepatocelular pelo consumo de alimentos, como o fubá.
Os resultados obtidos permitem concluir que a utilização do ELISA é adequada para uma determinação rápida, simples e com baixa utilização de solventes orgânicos de aflatoxinas em amostras de milho e derivados, desde que os resultados sejam sempre confirmados por outras técnicas alternativas, de modo a e evitar resultados falso-positivos e/ou falso-negativos.

\section{5 - REFERÊNCIAS BIBLIOGRÁFICAS}

[1] ABDULKADAR, A.H.W.; ABDULLA, A.A.; AL-JEDAH, J.H. Ocurrence of aflatoxin in commodities imported into Qatar, 1997-2000, Food Addit. Contam., v. 19, p. 666-670, 2002.

[2] ALI, N.; SARDJONO; YAMASHITA, A.; YOSHIZAWA, T. Natural co-occurrence of aflatoxins and Fusarium Mycotoxins (fumonisins, deoxynivalenol, nivalenol and zearalenone) in corn from Indonésia. Food Addit. Contam., v. 15, p. 377-384, 1998.

[3] ALlEN, J.C.; SMITH, C.J. Enzyme-linked immunosorbent assay kits for routine food analysis. Trends in Biotechnology, v. 5, p. 193-199, 1987.

[4] AOAC - 1995. Official methods of analysis of the Association of Official Analytical Chemists, $16^{\text {th }}$ The Association: Arlington, Washington.

[5] BERNER, D. Aflatoxin: test kit versus chemical methods. Inform., v. 3, p. 218-219, 1992.

[6] BHAT, R.V.; VASANTHI, S.; RAO, S.B.; RAO, N.R.; RAO, S.V.; NAGARAJA, K.V.; BAI, N.R.; PRASAD, K.; VANCHINATHAN, S.; ROY, R.; SAHA, S.; MUKHERJEE, A.; GHOSH, P.K.; TOTEJA, G.S.; SAXENA, B.N. Aflatoxin $B$ contamination in maize samples collected from different geographical regions of India - a multicentre study. Food Addit. Contam., v. 14, p. 151-156, 1997.

[7] BRASIL, Resolução RDC no 274 da Anvisa, de 15 de outubro de 2002. Diário Oficial da União, Brasília, 16 de outubro de 2002.

[8] BRASIL, Ministério da Agricultura. Portaria no 183 , de 21 de março de 1996. Diário Oficial da União, Seção I, p. 4.929, Brasília, 25 de março de 1996.

[9] CHU, F.S.; UENO, I. Production of antibody against aflatoxin $B_{1}$ Appl. Environ. Microbiol., v. 33, p. 1.125$1.128,1997$.

[10] CREPPY, E.E. Update of survey, regulation and toxic effects of mycotoxins in Europe. Toxicol. Lett., v. 127, p. 19-28, 2002.

[11] EATON, D.L.; GROPMAN, J.D. The toxicology of aflatoxins: human health, veterinary, and agricultural significance. San Diego (CA): Academic Press, 1994.

[12] ELLIS, W.O.; SMITH, J.P.; SIMPSON, B.K.; OLDHAM, J.H. Aflatoxins in food: occurrence, biosynthesis, effects on organisms, detection, and methods of control. Crit. Rev. Food Sci. Nutr., v. 30, p. 403-439, 1991.

[13] FAO - FOOD AND AGRICULTURE ORGANIZATION OF THE UNITED NATIONS, 1997. World regulations for mycotoxins. A compendium. FAO Food and Nutrition Paper 64, Rome, 1995.

[14] FREUND, J.E.; SIMON, G.A. Estatística aplicada: economia, administração e contabilidade, $9^{\mathrm{a}} \mathrm{ed}$., Porto Alegre: Bookman Companhia Editora, 1999.

[15] FURLONG, E.B.; SOARES, L.A.S.; VIEIRA, A.P.; DADALT, G. Aflatoxinas, ocratoxina A e zearalenona em 
alimentos da região sul do Rio Grande do Sul. Rev. Inst. Adolfo Lutz, v. 58, p. 105-111, 1999.

[16] GEMS/FOOD REGIONAL DIETS - GLOBAL ENVIRONMENT MONITORING SYSTEM - FOOD CONTAMINATION MONITORING AND ASSESSMENT PROGRAMME. Geneva (regional per capita consumption of raw and semi-processed agricultural commodities), WHO (World Health, Organization), 2003. Disponível em: http://www. who.int/foodsafety/chem/en/gems_regional_diet.pdf. Acesso em: 8 nov. 2004.

[17] GIMENO, A. Thin layer chromatographic determination of aflatoxins, ochratoxins, sterigmatocystin, zearalenone, citrinin, T-2 toxin, diacetoxyscirpenol, penicillic acid, patulin, and penitrem A. J. Assoc. Off. Anal. Chem. v. 62 , p. $579-585,1979$.

[18] GLORIA, E.M.; CIACCO, C.F.; LOPES FILHO, J.F.; ERICSSON, C.; AND ZOCCHI, S.S. Distribution of aflatoxin contamination in maize samples. Cienc. Tecnol. Aliment., v. 24, p. 71-75, 2004

[19] GLÓRIA, E.M.; FONSECA, H.; SOUZA, I.M. Ocurrence of mycotoxins in maize delivered to the food industry in Brasil. Trop. Sci., v. 37, p. 107-110, 1997.

[20] GOLDBLATT, L.A. (ed.), Aflatoxin scientific background, control, and implications. New York: Academic Press, 1969.

[21] GONZÁLEZ, H.H.L.; MARTÍNEZ, E.J.; PACIN, A.M.; RESNIK, S.L.; SYDENHAM, E.W. Natural co-occurrence of fumonisins, deoxyvalenol, zearalenone and aflatoxins in field trial corn in Argentina. Food Addit. Contam., v. 16, p. 565-569, 1999.

[22] HANSEN, T.J. Immunochemical methods for mycotoxin detection in food products. Trends Food Sci. Technol., v. 1, p. 83-88, 1990.

[23] HENNIGEN, M.R.; DICK, T. Incidence and abundance of mycotoxins in maize in Rio Grande do Sul, Brazil. Food Addit. Contam., v. 12, p. 677-681, 1995.

[24] HERRMAN, J.L.; YOUNES, M. Background to the ADI/TDI/PTWI. Regul. Toxicol. Pharmacol., v. 30, p. S109-S113, 1999.

[25] HUSSEIN, H.S.; BRASEL, J.M. Toxicity, metabolism, and impact of mycotoxins on humans and animals. Toxicology, v. 167, p. 101-134, 2001

[26] IBGE - Instituto Brasileiro de Geografia e Estatística, 2003. Aquisição alimentar domiciliar per capita anual, por grandes regiões, segundo os produtos. Pesquisa de orçamentos familiares 2002-2003, Brasília (DF). Tabelas 3.1.1 e 3.1.2. Disponível em: http://www.ibge. gov.br. Acesso em: 8 nov. 2004

[27] KUIPER-GOODMAN, T. Mycotoxins: risk assessment and legislation. Toxicology Letters, v. 82/83, p. 853859, 1995.

[28] LAZZARI, F.A. Umidade, fungos e micotoxinas na qualidade de sementes, grãos e rações, Curitiba: Ed. do Autor, 1993.

[29] LI, F.Q.; YOSHIZAWA, T.; KAWAMURA, O.; LUO, X.Y.; LI, Y.W. Aflatoxins an fumonisins in corn from the high-incidence area for human hepatocellular carcinoma in Guangxi, China. J. Agric. Food Chem., v. 49, p. 4.122-4.126, 2001

[30] MACHINSKI JR.; M., SOARES, L.M.V.; SAWAZAKI, E.; BOLONHEZI, D.; CASTRO, J.L.; BORTOLLETO, N. Aflatoxins, ochratoxin A and zearalenone in Brazilian corn cultivars. J. Sci. Food Agric., v. 81, p. 1.0011.007, 2001.

[31] MEDINA-MARTÍNEZ, M.S.; MARTÍNEZ, A.J. Mold occurrence and aflatoxin $B_{1}$ determination in corn samples in Venezuela. J. Agric. Food Chem., v. 48, p. 2.833-2.836, 2000.

[32] MILANEZ, T.V.; ATUI, M.B.; LÁZZARI, F.A. comparação entre imunoensaio e cromatografia em camada delgada na determinação de aflatoxnas, ocratoxina A e zearalenona em amostras de milho em grão e fubá. Rev. Inst. Adolfo Lutz, v. 57, n. 1, p. 65-71, 1998 .

[33] MILLER, J.D. Fungi and mycotoxins in grain: implications for stored product research. J. Stored Prod. Res., v. 31, n. 1, p. 1-16, 1995.

[34] MOSS. M.O. Risk assessment for aflatoxins in foodstuffs. Int. Biodeterior. Biodegrad., v. 50, p. 137-142, 2002.

[35] NEPOTE, M.C.; PIONTELLI, L.E.; SAUBOIS, A. Occurrence of Aspergillus flavus strains and aflatoxins in corn from Santa Fé, Argentina. Archivos Latinoamericanos de Nutrición, v. 47, p. 262-264, 1997.

[36] OLIVEIRA, C.A.F.; GERMANO, P.M.L. Aflatoxinas: conceitos sobre mecanismos de toxicidade e seu envolvimento na etiologia do câncer hepático celular. Rev. Saúde Pública, v. 31, p. 417-424, 1997.

[37] OLIVEIRA, M.S.; PRADO, G.; JUNQUEIRA, R.G. Comparação das técnicas de cromatografia em camada delgada e ELISA na quantificação de aflatoxinas em amostras de milho. Cienc. Tecnol. Aliment., v. 20, p. 369-374, 2000 .

[38] ONO, E.Y.S.; ONO, M.A.; FUNO, F.Y.; MEDINA, A.E.; OLIVEIRA, T.C.R.M.; KAWAMURA, O.; UENO, Y.; HIROOKA, E.Y. Evaluation of fumonisin-aflatoxin cooccurrence in Brazilian corn-hybrids by Elisa. Food Addit. Contam., v. 18, p. 719-729, 2001.

[39] PAPP, E.; H-OTTA, K.; ZÁRAY, G.; MINCSOVICS, E. Liquid chromatographic determination of aflatoxins. Microchem. J., v. 73, p. 39-46, 2002.

[40] PESTKA, J.J.; ABOUZIED, M.N.; SUTKINO .Immunological assays for mycotoxin detection. Food Technol., v. 49 , n. 2, p. 120-128, 1995.

[41] PICH, P.H.; NORDIN, N.S.D.; NOLL, I.B. Detecção de aflatoxinas em produtos derivados de milho comercializados na região de Porto Alegre (RS). In: Anais do IX Encontro Nacional de Micotoxinas (Brasil: Florianópolis), p. 120, 1998.

[42] PRZYLBYLSKI, W. Formation of aflatoxin derivatives on thin layer chromatographic plates. J. Assoc. Off. Anal. Chem., v. 58, n. 1, p. 163-164, 1975.

[43] SABINO, M.; LAMARDO, L.C.A ; INOMATA, E.I.; ICHIKAWA, A.H.; GIANNATTASIO, C.M.P. Ocorrência de aflatoxina $\mathrm{B} 1$ em produtos alimentícios e rações animais, consumidos no Estado de São Paulo e várias regiões do Brasil, no período de 1980 a 1987 . Rev. Inst. Adolfo Lutz, v. 48, n. 1/2, p. 81-85, 1988.

[44] SOARES, L.M.V. Micotoxinas: Um método para análise simultânea e incidência em alimentos comercializados na região de Campinas (SP). Campinas, 1987, Tese de doutorado, Fea/Unicamp.

[45] SOARES, L.M.V.; RODRIGUEZ-AMAYA, D.B. Survey of aflatoxins, ochratoxin A, zearalenone, and sterigmatocystin in some Brazilian foods by using multi-toxin 
thin-layer chromatographic method. J. Assoc. Off. Anal. Chem., Arlington, v. 72, p. 22-26, 1989.

[46] SOLOVEY, M.M.; SOMOZA, C.; CANO, G.; PACIN, A.; RESNIK, S. A survey of fumonisins, deoxyvalenol, zearalenone and aflatoxins contamination in corn-based food products in Argentina. Food Addit. Contam., v. 16, p. 325-329, 1999.

[47] STEYN, P.S. The biosynthesis of mycotoxins. Rev. Med. Vet., Toulouse, France, v. 149, n. 6, p. 469-478, 1998.

[48] SWEENEY, M.J.; DOBSON, A.D.W. Molecular biology of mycotosin biosynthesis. FEMS Microbiol. Lett., v. 175, p. 149-163, 1999.

[49] VARGAS, E.A.; PREIS, R.A.; CASTRO, L.; SILVA, C.M.G. Co-occurrence of aflatoxins $B_{1}, B_{2}, G_{1}$ e $G_{2}$ zearalenone and fumonisin in Brazilian corn. Food Addit. Contam., v. 18, p. 981-986, 2001.

[50] WHO - World Health Organization. (Environmental Health Criteria 11) Mycotoxins. Geneva: UNEP/WHO, p. $127,1979$.

\section{6 - AGRADECIMENTOS}

À Fundação Araucária pelo apoio financeiro, protocolo 248/2001, convênio 036/2003. À Coordenação de Aperfeiçoamento de Pessoal de Nível Superior (Capes) pela bolsa de estudos para o primeiro autor. E ao Conselho Nacional de Desenvolvimento Científico e Tecnológico (CNPq) pela bolsa de iniciação científica para o segundo autor. 